\title{
CRACKING OF SHCC DUE TO REINFORCEMENT CORROSION
}

\author{
${ }^{*}$ Microlab, Delft University of Technology \\ Delft, the Netherlands \\ e-mail: \{b.savija;m.lukovic;erik.schlangen\}@ tudelft.nl \\ ${ }^{\dagger}$ CTL Group \\ Skokie, IL USA \\ e-mail: jpacheco@ctlgroup.com
}

BRANKO ŠAVIJA*, MLADENA LUKOVIĆ* ${ }^{*}$,JOSÉ PACHECO ${ }^{\dagger}$, AND ERIK SCHLANGEN*

Key words: SHCC, Corrosion induced cracking, Durability, CT Scanning

\begin{abstract}
Reinforcement corrosion is the most important deterioration mechanism affecting reinforced concrete infrastructures. After corrosion starts, expansive pressures are exerted onto the surrounding concrete, causing cracking and spalling of the cover concrete. The amount of cover cracking can possibly be reduced by using strain hardening cementitious composites (SHCCs). In this work, the ability of strain hardening cementitious composite to resist cracking due to corrosion of reinforcement is studied. An accelerated corrosion experiment is performed to speed up the corrosion process. Micro-computed X-ray tomography technique (CT-scanning) was used for monitoring rust formation during accelerated corrosion of reinforcement and subsequent cover cracking. Development of cracks in SHCC specimen was compared to a reference specimen. While the SHCC specimen developed a large number of small cracks, the reference specimen exhibited extensive spalling due to corrosion. The SHCC specimen showed superior performance compared to the reference specimen due to its multiple microcracking ability. SHCC proved to be an excellent alternative to brittle cementitious materials when corrosion induced cracking of the cover is a concern.
\end{abstract}

\section{INTRODUCTION}

Corrosion of steel reinforcement in reinforced concrete structures is a common cause of deterioration, resulting in unforeseen maintenance and repair costs. The steel in concrete is initially protected from active corrosion by a passive layer, which forms on its surface in the alkaline environment provided by the concrete. However, this protective layer can break down, either due to carbonation or chloride ingress. An electrochemical process of steel corrosion, which causes the dissolution of iron and formation of iron oxides, then takes place. The resulting rust occupies a larger volume than its parent steel and exerts internal pressure on the surrounding concrete. Cracking of the cover occurs during the pressure buildup, due to the relatively low tensile strength of concrete. Cracking of the concrete cover is usually the first visible sign of the ongoing deterioration. It also speeds up the corrosion deterioration, as cracks enable faster ingress of chloride, carbon dioxide, and moisture [1].

Very little research has focused on nondestructive and continuous monitoring of the cracking process caused by reinforcement corrosion. Lately, non-destructive techniques, such as acoustic emission [2], x-ray attenuation and digital image correlation [3], have been used. Another non-destructive technique, namely micro-computed tomography (CT scan- 
ning), has been used recently for studying concrete fracture (e.g. [4]) and corrosion processes [5]. Computed Tomography enables non-destructive and qualitative measurements of volume quantities which are not accessible to other methods. The nature of the technique enables its use for monitoring of corrosion and subsequent cracking of concrete, which is one aim of this study.

In this work, the benefits of using a fiber reinforced cementitious material - strain hardening cementitious composite (SHCC) - are studied. SHCC is characterized by formation of narrow microcracks and strain hardening behavior [6]. When subjected to reinforcement corrosion, SHCC exhibits significant anti-spalling ability compared to conventional mortar [7,8]. In order to show the superior performance of SHCC under corrosion induced pressure, computed tomography technique is used herein. Furthermore, elastic modulus of the rust layer, which is an important parameter in numerical models, nanoindentation is used at the end of the corrosion experiment.

\section{EXPERIMENTAL APPROACH}

\subsection{Materials and methods}

Materials used in the SHCC mixture were Ordinary Portland Cement (CEM I 42.5N), limestone powder, blast furnace slag (BFS), water, superplasticizer, and polyvinyl alcohol (PVA) fibers. Two variations of the mixture were used for specimen fabrication: one with PVA fibers (SHCC mixture), and one without fibers (control mixture). No chlorides were added to the mix, as corrosion was accelerated by applying an electrical current. The mixture proportions are given in table 1 . Note that the control mixture is the same as the SHCC mixture, but without the PVA fibers. As reinforcement, a smooth carbon steel rod with a diameter of $6 \mathrm{~mm}$ was used. In order to minimize beam-hardening effect due to the presence of dense steel, a hole was drilled in the steel bars. Hence, bars used in the study had the inner diameter of $4.2 \mathrm{~mm}$ and the outer diameter of $6 \mathrm{~mm}$. This inside of the bars was filled with epoxy resin, in order to prevent the additional formation of rust there (see figure 1 ).

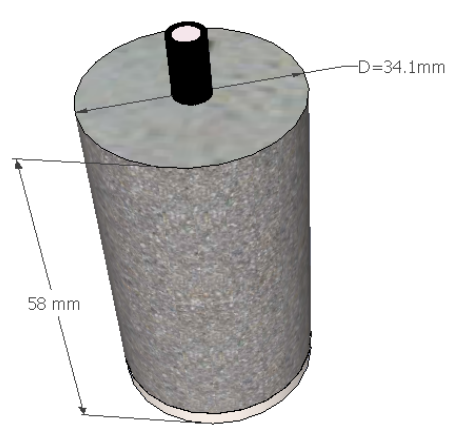

Figure 1: Specimen geometry used in the experiments

Table 1: SHCC mix proportions (weight \%) (developed by Zhou et al. [9])

\begin{tabular}{cc}
\hline Ingredient & Quantity \\
\hline CEM I 42.5N & 0.6 \\
\hline Limestone powder & 2 \\
\hline Blast furnace slag & 1.4 \\
\hline Water/powder ratio & 0.26 \\
\hline Superplasticizer & 0.02 \\
\hline PVA fiber (by volume, \%) & 2 or 0 \\
\hline
\end{tabular}

Two cylindrical specimens were fabricated, one using the SHCC, and the other using the control mixture. The specimens had a diameter of $34.1 \mathrm{~mm}$ and length of about $58 \mathrm{~mm}$, with the steel rod positioned in the middle of each cylinder (figure 11). About $10 \mathrm{~mm}$ of steel was protruding from each specimen, in order to enable connection with a direct current (DC) power supply used in the accelerated corrosion test. The steel rod was fixed in place using epoxy resin 24 hours prior to casting, and hence the bottom $3 \mathrm{~mm}$ of each cylinder was made out of epoxy. The freshly cast specimens were consolidated using a vibrating table. The specimens were sealed and left in a climate room $\left(20^{\circ} \mathrm{C}\right.$ and more than $95 \%$ relative humidity) for 10 days, before being demolded and prepared for the accelerated corrosion test. 


\subsection{Accelerated corrosion test}

For the micro-computed tomography (CT) tests, two specimens were used (SHCC and control mixture, i.e. without PVA fibers). Each specimen was connected to a DC regulator to enforce corrosion. A titanium mesh was wrapped around each specimen in order to act as a counter electrode. During the exposure, each specimen was immersed in a container with saturated calcium hydroxide $\left(\mathrm{Ca}(\mathrm{OH})_{2}\right)$ solution. The applied voltage was varied during the test, in order to cause increase of damage between scans (figure 2).
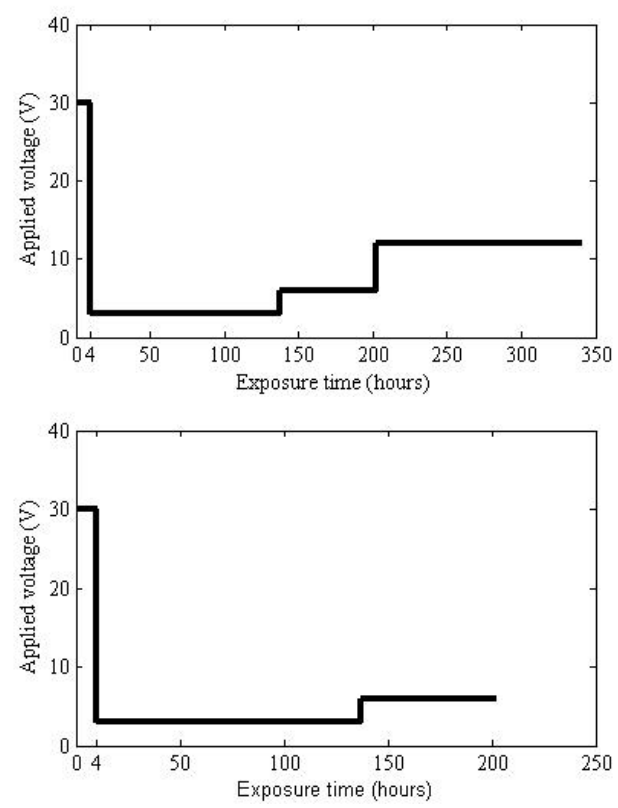

Figure 2: Applied voltage for both specimens (topSHCC, bottom-reference)

\subsection{Micro-computed tomography tech- nique}

The internal structure of (reinforced) concrete after different exposure times were monitored by using three dimensional microcomputed tomography (CT scanning). While mostly used in diagnostic medicine, CT scanning is increasingly used in non-destructive testing, also of cementitious materials. Previous studies showed promising results [4]5]. The aim of CT scanning is to non-destructively obtain detailed information about the internal structure of a specimen. CT images are 3D maps of X- ray absorption in the material [4]. Multiple Xray images of a specimen are taken at different angles. Using a reconstruction algorithm, a 3D image of the internal structure of a specimen is produced. The measurement principle is shown in figure 3 .

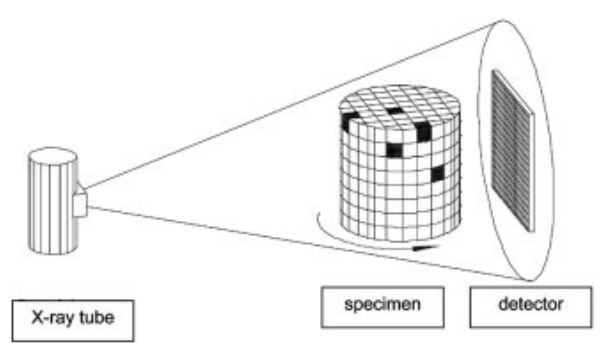

Figure 3: Measurement principle of computed tomography [5]

During the exposure period of the samples, they were periodically removed from the corrosion cell in order to perform a CT scan. Each sample was first scanned prior to the accelerated corrosion testing. Then, SHCC sample was scanned in total five times during the corrosion test, while the control mixture sample was tested only four times, because excessive damage had already occurred at that point (Table 2.3.

Table 2: A scheme of performed scans and exposure times

\begin{tabular}{cccc}
\hline Scan & Exposure duration (h) & SHCC & Control \\
\hline 0 & 0 & + & + \\
\hline 1 & 4 & + & + \\
\hline 2 & 94 & + & + \\
\hline 3 & 137 & + & + \\
\hline 4 & 202 & + & + \\
\hline 5 & 340 & + & - \\
\hline
\end{tabular}

Phoenix Nanotom X-ray system was used for data acquisition. During the scan, a specimen is positioned on a rotating stage. A marker was placed on each specimen, in order to try to fit the sample at almost the same position during every scan. During each scan, 1440 tomographic images were taken over a complete $360^{\circ}$ rotation. A $0.2 \mathrm{~mm}$ copper filter was 
used to decrease the beam hardening effect. A single scan took about 90 minutes to perform. Achieved voxel size was about $16 \mu \mathrm{m}$. Total scanned height of the sample was about $36 \mathrm{~mm}$.

\subsection{Nanoindentation of the rust layer}

After the last CT scan, both specimens were vacuum impregnated using fluorescent epoxy. They were then carefully cut perpendicular to the steel bar. A slice from each sample was selected and prepared for nanoindentation testing. Agilent Nano Indenter G200 with a diamond Berkovich tip (i.e. a three-sided pyramidal diamond) was used for nano-indentation tests. A quartz standard was indented before and after each test series to ensure accuracy. Several series of indents were performed on a tightly spaced grid, with spacing of $20 \mu \mathrm{m}$ (for all tested locations). The indentation depth was set to $2000 \mathrm{~nm}$.In the E modulus calculation, Poisson's ratio of the indented material (steel, rust, and cementitious material) was set to 0.25 in the calculations. More details about the procedure are given in [10].

\section{RESULTS AND DISCUSSION}

As difference in density between the cementitious material and steel is large, resulting in large difference in X-ray attenuation coefficients, unprocessed CT images are dark, with steel being very bright. Therefore, a number of $\mathrm{CT}$ images have been processed manually in order to reveal the most interesting features. The aim was to emphasize four different phases, namely air voids and cracks, cementitious material, corrosion products, and non-corroded steel. They are displayed as white, black, red, and blue, respectively. Due to beam hardening effects, the inside of the hollow steel rebar is affected. Hence it has been filled with blue color for clarity in the displayed CT images.

\subsection{SHCC specimen}

\subsubsection{CT scanning results}

As shown in table 2.3. SHCC specimen was scanned in total six times, including an initial scan before the accelerated corrosion exposure. A single vertical slice was selected, and its processed CT image during each of the scans is shown in figure 4. The selected slice also shows a large air void close to the steelconcrete interface, available for deposition of dissolved corrosion products. Already in scan 1 , several cracks are clearly visible. Subsequent scans show the formation of new cracks, without formation of a single major crack. The rust layer around the steel bar is of relatively uniform thickness, with the exception of the contact with the large air void. These scans also suggest that the corrosion products, indeed, penetrate into open spaces (in this case, an air void) thereby relieving some of the pressure which would otherwise be exerted onto the concrete.

In figure 5, a zoomed-in image of the steelcementitious material interface is shown (at scan 5). The penetration of dissolved rust into the large air void is clearly visible. The rust layer is, at this stage, not uniform. It seems that the corrosion affects the steel more at the contact with the air void, resulting in a sort of a pit. It is possible that oxygen, contained in the air void, could enhance the rate at which the cathodic reaction occurs. Since the degradation due to corrosion is limited by the rate of the slowest reaction (anodic or cathodic), a non-uniform deterioration occurs because the cathodic reaction next to the air void is faster than in the bulk material. Some penetration of rust into a crack is also observed. 


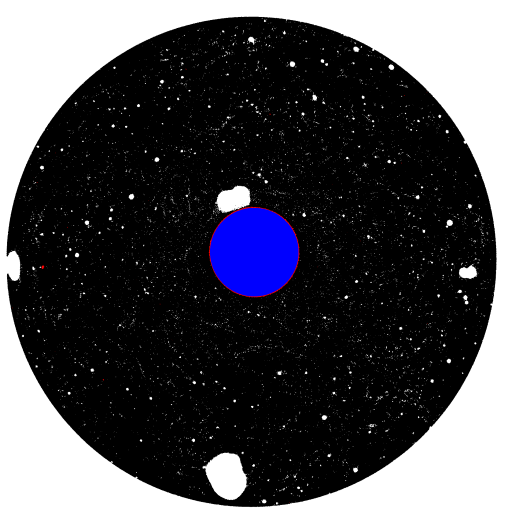

(a) Scan 0

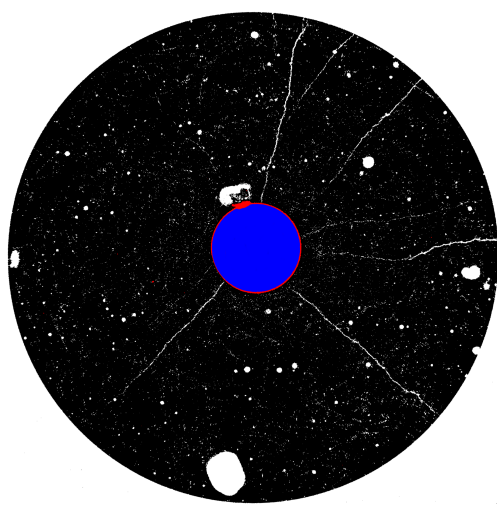

(c) Scan 2

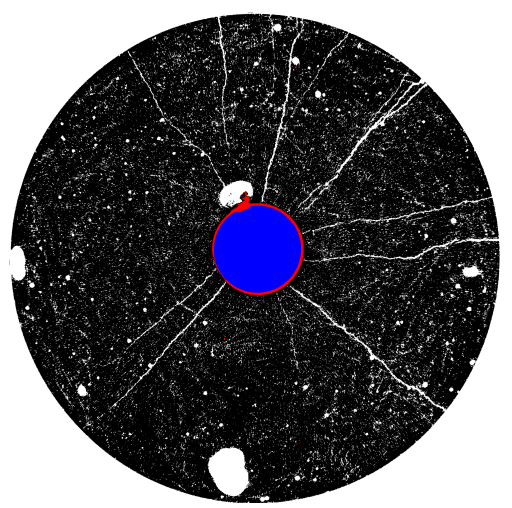

(e) Scan 4

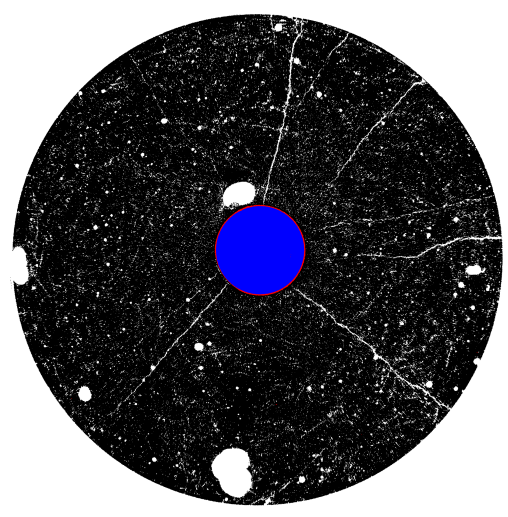

(b) Scan 1

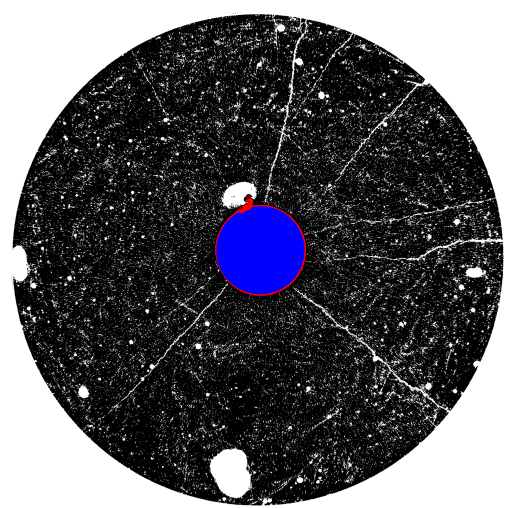

(d) Scan 3

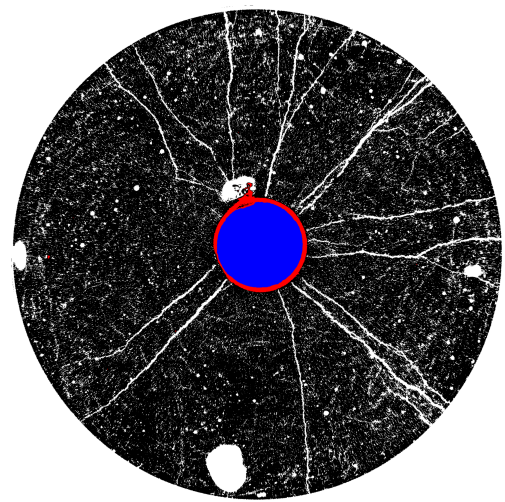

(f) Scan 5

Figure 4: Processed CT images of the cracking sequence in the SHCC sample 


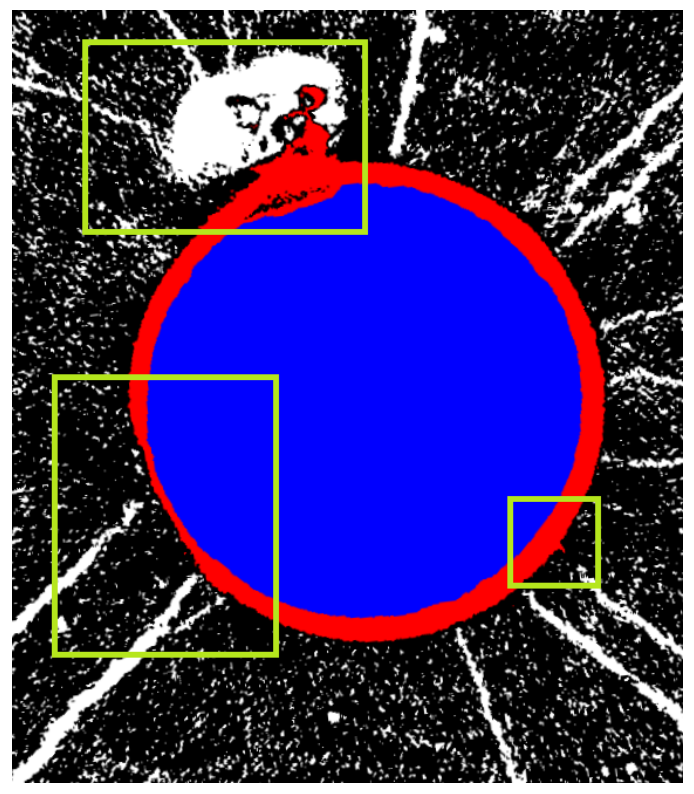

Figure 5: Steel-cementitious material interface at scan 5 of the SHCC sample. Top-penetration of rust into an air void; left: non-uniform rust layer; right: penetration of rust into a crack

Figure 6 shows a number of processed CT slices from scan 5 , clearly displaying movement of corrosion products into an open crack.

\subsubsection{Nanoindentation results}

Images taken in the nanoindenter and overlapped with Young's modulus measurements are shown in Figure 7 .

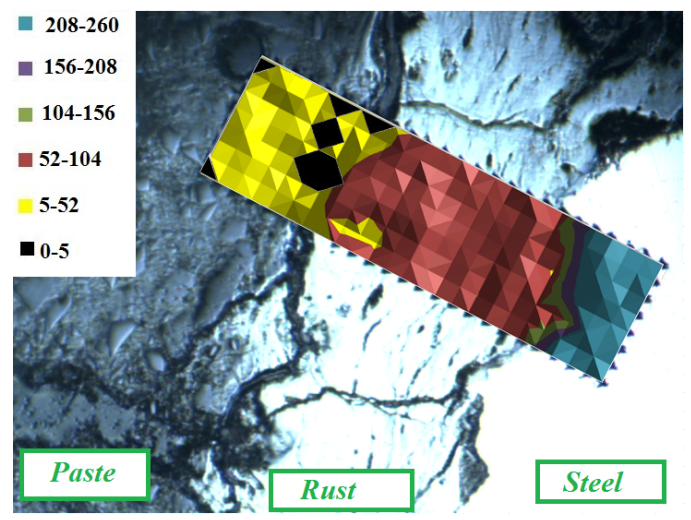

Figure 7: E modulus distributions in the steelcementitious material interface of the SHCC sample $(G P a)$

A clear distinction between different materials can be noticed, depending on their E modulus values. If only the indents that are within the rust layer are averaged, Young's modulus of around $67.9 \mathrm{GPa}$ is found.

\subsection{Reference specimen}

\subsubsection{CT scanning results}

The control mixture specimen was scanned in total five times, including the initial scan before the accelerated corrosion exposure (table 2.3. Again, a single slice was selected, and the processed CT images during each of the scans are displayed in figure 8. Already in scan 1, one large crack formed, accompanied by three smaller cracks. The largest crack was also clearly visible from the outside of the specimen, while the smaller cracks didn't reach the surface of the specimen at this stage. Scan 2 shows widening of already existing cracks, accompanied by formation of a new crack. These cracks are wider at scan 3 , and at scan 4 , a large piece of the cementitious material has spalled. At this point, the accelerated corrosion exposure was stopped.

What is interesting to see is that the rust layer around the steel bar is non-uniform already at scan 1. At this point already, excessive cracking has occurred. The same trend can be observed in scans 2-4. Also, a discontinuity seems to form between the rust layer and the cementitious material. It seems to increase with exposure, i.e. with the increase in damage. This is probably due to partial leaching out of dissolved corrosion products through open cracks, as discussed later.

Figure 9 shows a zoomed-in image of the steelcementitious material interface at scan 4 . The gap which forms between the rust layer and the material matrix is visible. The corrosion layer seems to be of a non-uniform density at this stage, resulting in a seemingly layered structure (shown as black spots within the red layer). Some penetration of rust into a crack is also observed here. 


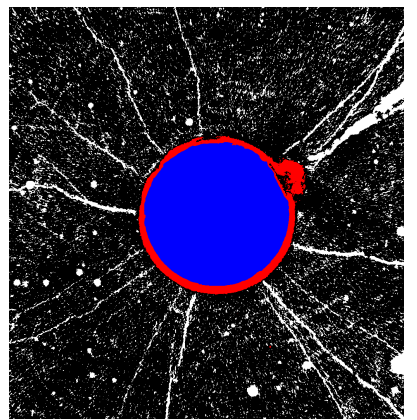

(a)

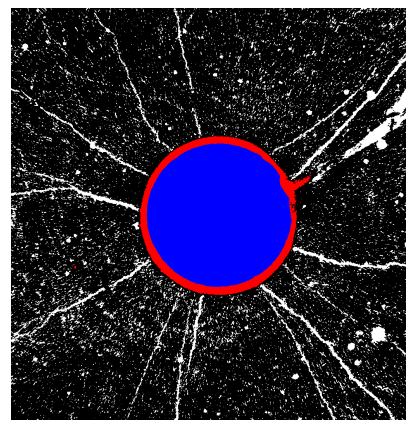

(c)

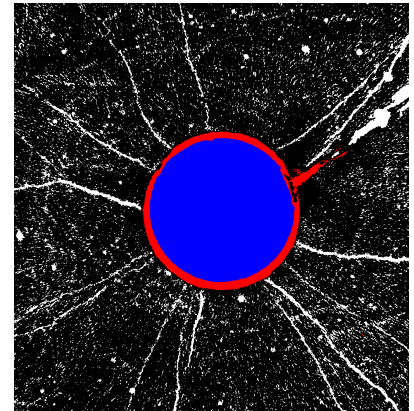

(b)

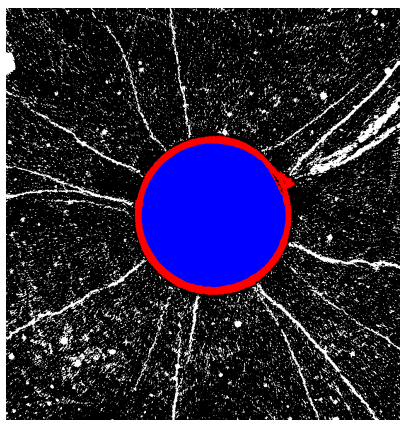

(d)

Figure 6: Penetration of corrosion products into an open crack in the SHCC sample (at scan 5)

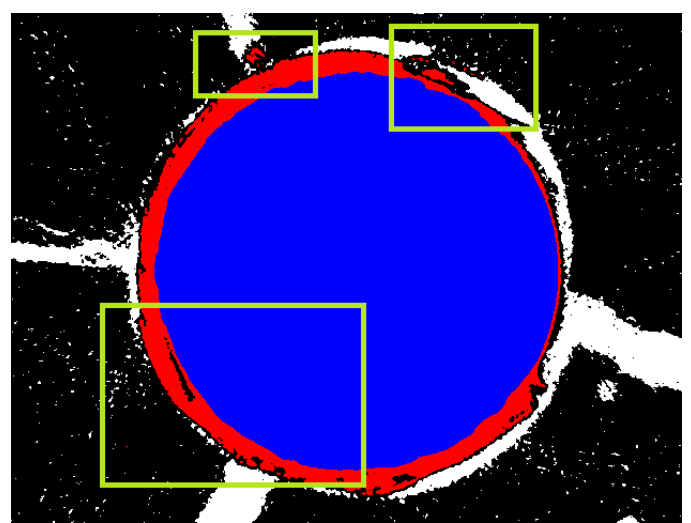

Figure 9: Steel-cementitious material interface at scan 4 of the control mixture sample. Top left-penetration of rust into into a crack; top right and bottom: non-uniform density within the rust layer.

\subsubsection{Nanoindentation results}

Images taken in the nanoindenter and overlapped with Young's modulus measurements for the reference specimen are shown in Figure 10.

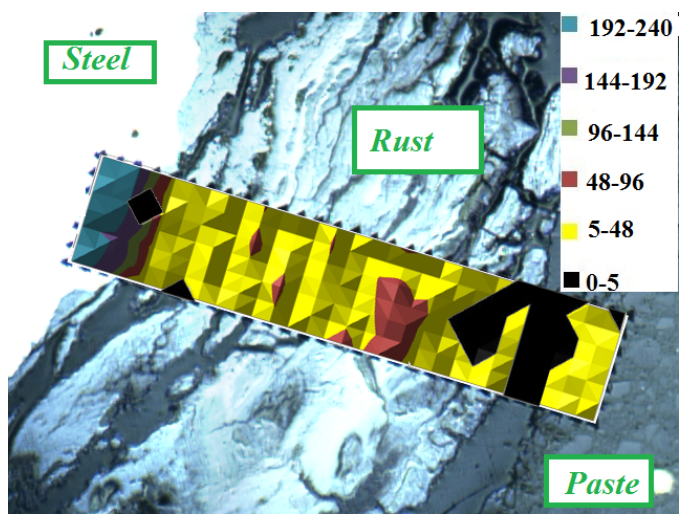

Figure 10: E modulus distributions in the steelcementitious material interface of the reference sample (GPa)

Unlike the SHCC specimen, in figure 10 it is difficult to clearly distinguish the indents belonging to the rust based on their E modulus value. Here, the layer between the intact steel and the cementitious material is composed of rust layers and epoxy resin. 


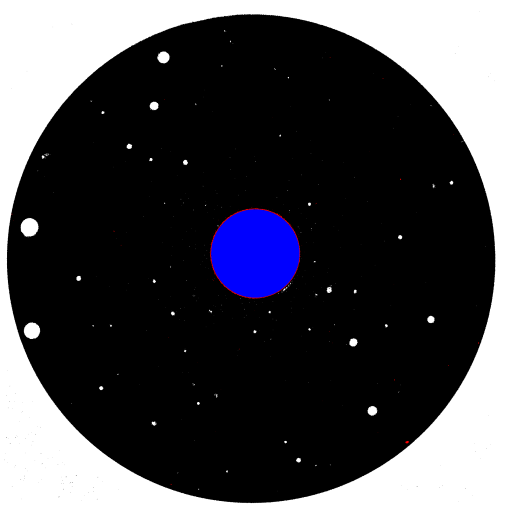

(a) Scan 0

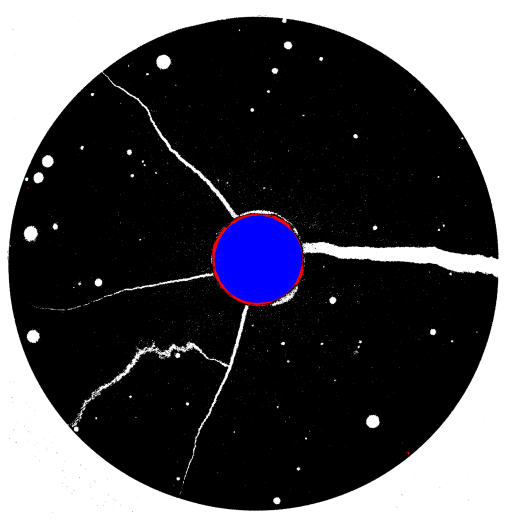

(c) Scan 2

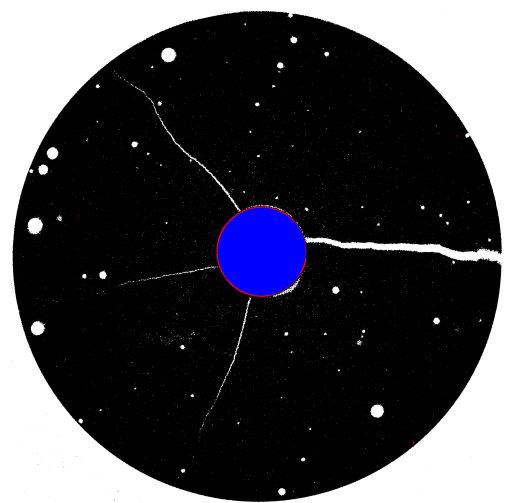

(b) Scan 1

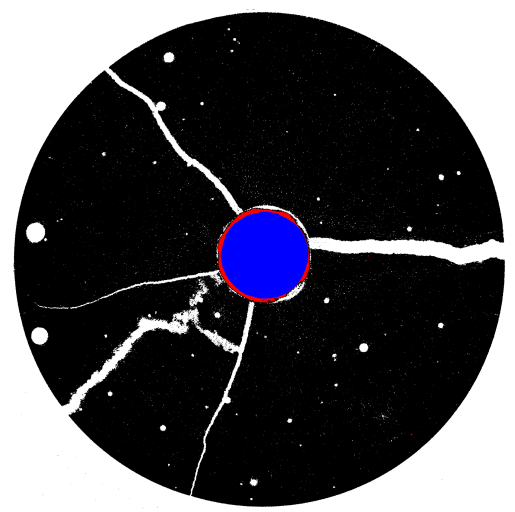

(d) Scan 3

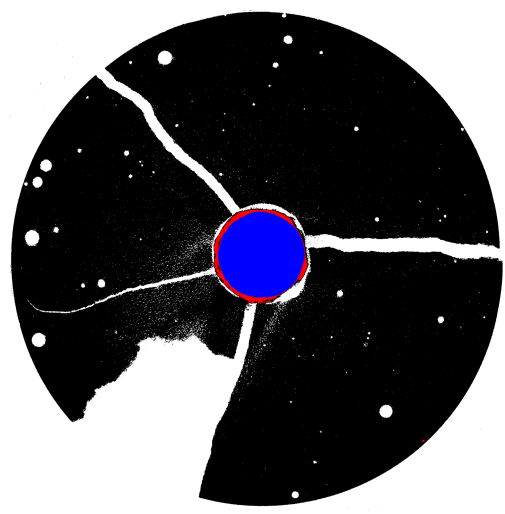

(e) Scan 4

Figure 8: Processed CT images of the cracking sequence in the control mixture sample 


\subsection{Discussion of CT scan results}

Presented results demonstrate the applicability of the X-ray computed tomography technique for studying corrosion induced cracking in cementitious materials. The sequence of cracking over time can be followed, as demonstrated in figures 4 and 8 . This is an improvement compared to conventional X-ray attenuation measurements [3], where averaging of $\mathrm{X}$ ray attenuation coefficients in one direction is present, making it impossible to observe and monitor, for example, discrete voids and cracks. The size of cracks which can be detected by the CT scanning technique is limited by its resolution (about $16 \mu \mathrm{m}$ per voxel in the current research). This, of course, means that some very small cracks may go unnoticed. The same goes for pores and air voids. Also, due to the finite pixel size, some averaging is present. This results in, for example, a thin red layer around the steel in figure 4, which suggests a 1 pixel wide layer of corrosion even prior to the exposure. This is certainly not the case. Nevertheless, the increase in the corrosion layer thickness over time can be monitored, as shown in figure 4 and 8 . These scans also suggest that the corrosion products, indeed, penetrate into open spaces, such as air voids and cracks, thereby relieving some of the pressure which would otherwise be exerted onto the concrete. This is, especially, clear in figures 5 and 6 . In addition, figures 8 and 9 suggests that a discontinuity forms at the steel-cementitious material interface after cracking occurs, especially close to large cracks. Also, close to large cracks, there is a pronounced non-uniformity of the corrosion layer thickness, which is especially noticeable in the control mixture specimen. This would go to suggest that some of the corrosion products dissolved in the calcium hydroxide $\left(\mathrm{Ca}(\mathrm{OH})_{2}\right)$ solution and leached out. It is possible that this process was aided by the presence of the cathode (i.e. the counter electrode) wrapped around the specimen. A modeling approach of Ožbolt et al. [11], who simulated the movement of red rust as a diffusion problem, seems promising in that respect. The higher "diffusivity" of large cracks, with respect to rust transport, indeed explains the observations. The quantification of this effect, however, remains an issue. Even so, the importance of taking this relief mechanism into account in numerical models is clear [11, 12].

When comparing the two tested specimens, it is clear that the control mixture specimen exhibits more brittle behavior. Already at an early stage of the test, a large crack has occurred in the specimen. On the other hand, the SHCC specimen showed high resistance to the pressure caused by steel bar corrosion. Even at the end of the exposure, no single crack has localized. Instead, the number of cracks kept increasing, and to a lesser extent their width. This can be attributed to its high deformational capacity compared to the brittle control mixture [6]. Also, due to its small crack widths, the SHCC specimen keeps the rust layer confined together, unlike the control mixture specimen (figures 6 and 9). This would also suggest that the SHCC specimen was subjected to more internal pressure, although this was not measured. The performance of the SHCC specimen was superior in terms of cracking resistance, similar to the study of Sahmaran et al. [7].

In figure 11, SEM images (backscatter electron mode) of the rust layer in SHCC and the reference specimen at the end of the experiment are shown. It can be clearly seen that the rust is quite compact and well confined in the SHCC specimen, while it shows a layered structure in the reference specimen. This probably means that the SHCC specimen takes up much more pressure compared to the reference specimen, due to the higher stiffness of the rust layer. This has been also shown by nanoindentation experiments [13]. 


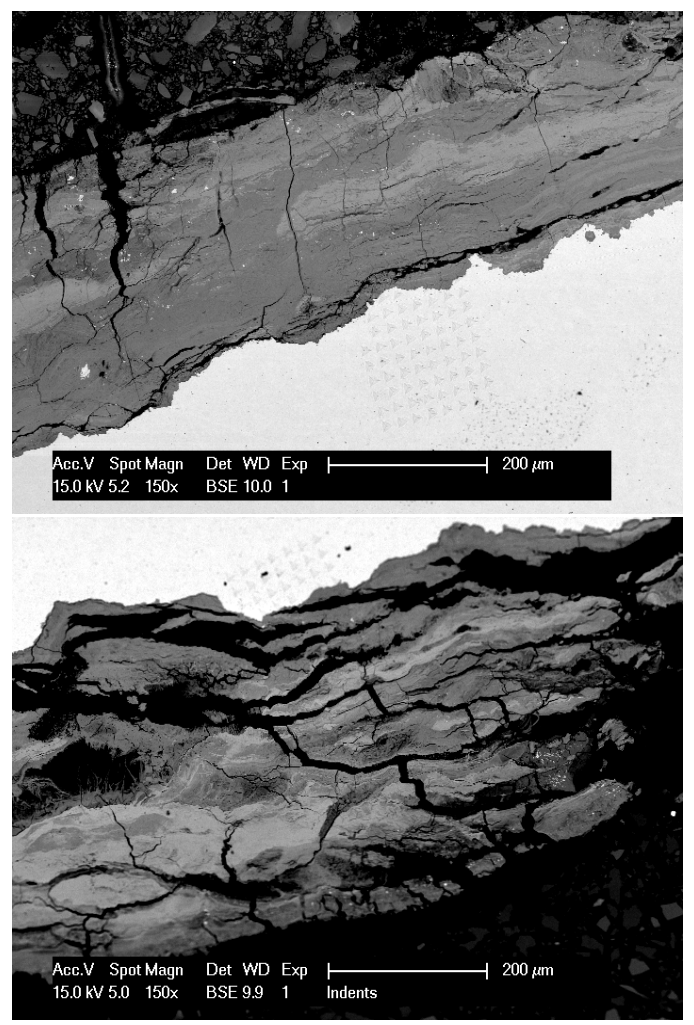

Figure 11: BSE images of the corrosion layer at the end of the experiment (top-SHCC, bottom-reference)

\subsection{Discussion of nanoindentation results}

$\mathrm{E}$ modulus values for confined rust (i.e. SHCC specimen) are found to be between 5070GPa [13]. In the control mixture specimen, the (tested) rust layer is composed of layers of iron oxide intertwined by epoxy, which penetrated into the interlayer cracks, which makes it difficult to determine a single value for the $\mathrm{E}$ modulus.

\subsection{Modeling}

It is also possible to simulate the process of corrosion induced cracking using the Delft lattice model [12]. In the model, the material is discretized as a set of beam elements which can transfer forces [14]. Pressure induced by reinforcement corrosion is simulated by applying external forces around the position of the rebar [12]. It depends on the modulus of elasticity of the rust, porosity around the bar, and concrete (micro) cracking because a part of the corrosion product will go into pores and cracks and release the pressure. The correlation is, therefore, very complex and is not linear. The proposed procedure for determination of the corrosion induced pressure on the surrounding concrete by knowing the rebar section loss is described in [12]. To simulate the strain hardening behavior using the lattice model, discrete fibers are dispersed in the matrix [15].

Crack patterns for both the SHCC specimen and the control specimen are shown in figure 12. The simulated crack patterns mimic the experimental observations quite well. More information about the modeling procedure and additional experiments can be found in reference [16].
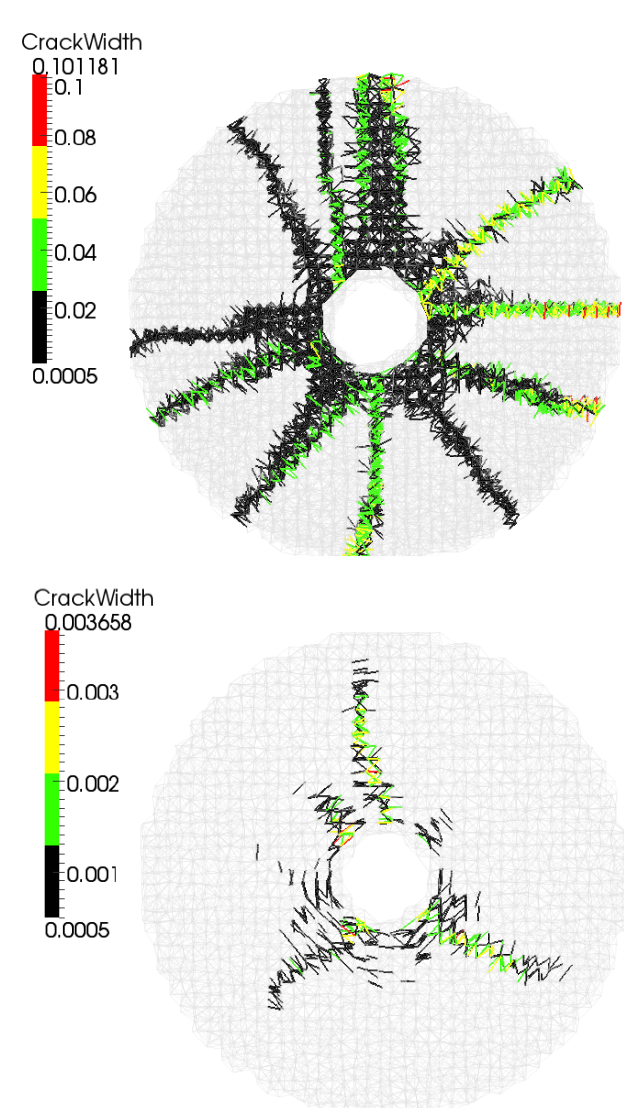

Figure 12: Lattice simulation of corrosion induced cracking. Top- SHCC (imposed internal pressure of 103.58MPa); bottom- control (imposed internal pressure of $17.32 \mathrm{MPa})$.

\section{SUMMARY AND CONCLUSIONS}

In this study, the applicability of X-ray micro-computed tomography to monitor cor- 
rosion induced cracking of cementitious composites was tested. Furthermore, the efficiency of SHCC in suppressing the damage caused by corrosion induced expansion was examined. This research has led to following conclusions:

1. Micro-computed X-ray tomography (i.e. CT scanning) is a valuable tool for nondestructively studying fracture in cementitious materials. Findings regarding crack initiation and propagation in specimens subjected to internal pressure due to rust expansion are valuable for validation and fine-tuning of numerical models.

2. Differences in X-ray attenuation coefficients between the cementitious matrix, rust, and intact steel, enable one to resolve the distribution of each of these phases in space. As a consequence, formation of a rust layer around the steel, discrete cracking, and movement of rust into open cracks and air voids have all been observed.

3. Penetration of rust into open spaces causes a non-uniform rust layer to occur. This is especially noticeable close to large cracks and air voids. Dissolved rust seems to migrate into open spaces, without causing expansive pressure on the concrete.

4. SHCC specimen showed great resistance to corrosion induced cracking compared to the control mixture specimen. Even at the end of the test, no single wide crack has localized. Instead, a large number of relatively narrow cracks has formed. In contrast, the control mixture specimen had already shown extensive spalling at that stage.

5. The Young modulus of the rust layer changes depending on the level of confinement provided to it by the surrounding material. In the confined state, the rust layer exhibits relatively uniform mechanical and chemical properties. The Young modulus of confined rust was found to be between 49.4-67.9 GPa. Once extensive cracking occurs, the rust layer is no longer of uniform density. This is caused by lack of confinement provided by the surrounding cementitious material, which leads to occurrence of micro gaps within the rust layer itself, and also results in lower Young modulus values of the layer as a whole.

\section{ACKNOWLEDGEMENTS}

Financial support by the Dutch Technology Foundation (STW) for the project 10978: Measuring, Modelling, and Monitoring Chloride ingress and Corrosion initiation in Cracked Concrete (M3C4) is gratefully acknowledged.

\section{REFERENCES}

[1] Šavija, B., Schlangen, E., Pacheco, J., Millar, S., Eichler, T. and Wilsch, G., 2014. Chloride ingress in cracked concrete: a laser induced breakdown spectroscopy (LIBS) study. Journal of Advanced Concrete Technology, 12(10), pp.425-442.

[2] Ohtsu, M. and Uddin, F.A., 2008. Mechanisms of corrosion-induced cracks in concrete at meso-and macro-scales. Journal of Advanced Concrete Technology, 6(3):419-429.

[3] Michel, A., Pease, B.J., Geiker, M.R., Stang, H. and Olesen, J.F., 2011. Monitoring reinforcement corrosion and corrosion-induced cracking using nondestructive x-ray attenuation measurements. Cement and Concrete Research, 41(11):1085-1094.

[4] Trainor, K.J., Foust, B.W. and Landis, E.N., 2012. Measurement of energy dissipation mechanisms in fracture of fiber-reinforced ultrahigh-strength 
cement-based composites. Journal of Engineering Mechanics, 139(7):771-779.

[5] Beck, M., Goebbels, J. and Burkert, A., 2007. Application of Xray tomography for the verification of corrosion processes in chloride contaminated mortar. Materials and Corrosion, 58(3):207-210.

[6] Li, V.C., Horii, H., Kabele, P., Kanda, T. and Lim, Y.M., 2000. Repair and retrofit with engineered cementitious composites. Engineering Fracture Mechanics, 65(2):317-334.

[7] Sahmaran, M., Li, V.C. and Andrade, C., 2008. Corrosion resistance performance of steel-reinforced engineered cementitious composite beams. ACI Materials Journal, 105(3).

[8] Chandra Paul, S. and van Zijl, G.P.A.G., 2014. Crack Formation and Chloride Induced Corrosion in Reinforced Strain Hardening Cement-Based Composite (R/SHCC). Journal of Advanced Concrete Technology, 12(9):340-351.

[9] Zhou, J., Qian, S., Beltran, M.G.S., Ye, G., van Breugel, K. and Li, V.C., 2010. Development of engineered cementitious composites with limestone powder and blast furnace slag. Materials and Structures, 43(6):803-814.

[10] Luković, M., Šavija, B., Dong, H., Schlangen, E., \& Ye, G.,2014. Micromechanical study of the interface properties in concrete repair systems. Journal of Advanced Concrete Technology, 12(9):320339.
[11] Ožbolt, J., Oršanić, F., Balabanić, G. and Kuśter, M., 2012. Modeling damage in concrete caused by corrosion of reinforcement: coupled 3D FE model. International Journal of Fracture, 178(1-2):233244.

[12] Šavija, B., Luković, M., Pacheco, J. and Schlangen, E., 2013. Cracking of the concrete cover due to reinforcement corrosion: a two-dimensional lattice model study. Construction and Building Materials, 44:626-638.

[13] Šavija, B., Luković, M., Hosseini, S.A.S., Pacheco, J. and Schlangen, E., 2015. Corrosion induced cover cracking studied by $\mathrm{X}$-ray computed tomography, nanoindentation, and energy dispersive X-ray spectrometry (EDS). Materials and Structures, 48:2043-2062.

[14] Schlangen, E. and Qian, Z., 2009. 3D modeling of fracture in cement-based materials. Journal of Multiscale Modelling, 1(02):245-261.

[15] Luković, M., Dong, H., Šavija, B., Schlangen, E., Ye, G. and van Breugel, K., 2014. Tailoring strain-hardening cementitious composite repair systems through numerical experimentation. Cement and Concrete Composites, 53:200-213.

[16] Luković, M., 2016. Influence of interface and strain hardening cementitious composite (SHCC) properties on the performance of concrete repairs, $\mathrm{PhD}$ Thesis, Delft University of Technology, the Netherlands. 